*Advogado. Graduado em Direito pela PUC-Campinas.E-mail: thiago.vazz@outlook.com

\footnotetext{
**Professor do Programa de PósGraduação em Direito da PUCCampinas. Doutor em Filosofia e Teoria Geral do Direito pela USP. E-mail: mastrodi@puccampinas.edu.br
}

\section{O compliance na Administração Pública: a realidade brasileira submetida A NORMAS DE INTEGRIDADE}

\author{
Compliance in the Public Administration: the \\ BRAZILIAN REALITY FACED BY NORMS OF INTEGRITY
}

\section{Thiago Vaz* Josué Mastrodi**}

Como citar: VAZ, Thiago; MASTRODI, Josué. O compliance na Administração Pública: a realidade brasileira submetida a normas de integridade. Revista do Direito Público, Londrina, v. 16, n. 2, p. 64-89, ago. 2021. DOI: 10.5433/24157-108104-1.2021v16 n2p. 64. ISSN: 1980-511X

Resumo: Este artigo tem como objeto de estudo o instituto do Compliance e sua aplicabilidade pela Administração Pública frente à realidade brasileira atual. Expõem-se os caracteres mais importantes desse instituto, apresentando-o, de início, em sua construção originalmente desenvolvida em outros países e, posteriormente, em suas especificidades nacionais. Para melhor entendimento, buscamos a experiência do Compliance no setor privado, onde os pilares desse instituto foram fundados. Analisase a positivação de normas de integridade no ordenamento jurídico pátrio e sua efetiva realização pelo poder Executivo, utilizando-se o tipo de pesquisa qualitativa, em que são coletadas informações que, posteriormente, são reunidas, analisadas e interpretadas de modo a elucidar os objetivos do presente artigo. Por derradeiro, apresenta-se um balanço dos cinco anos desde a promulgação da Lei Anticorrupção brasileira, resultando no apontamento de algumas conclusões sobre o tema.

Palavras-chave: Compliance; Administração pública; Lei anticorrupção; Lei das estatais.

Abstract: This article aims to study the Compliance institute and its applicability by the Public Administration in face of the current Brazilian reality. The most important characteristics of this institute are exposed, presenting it, at first, in its original construction developed in other countries and, later, in its national specificities. For a better understanding, we seek the experience of Compliance in the private sector, where the pillars of this institute were founded. The positivization of integrity norms in the Brazilian legal system and their effective 
implementation by the executive branch is analyzed using qualitative research, in which information is collected, gathered, analyzed and interpreted in order to elucidate the objectives of this article. Finally, a review of the five years since the enactment of the Brazilian Anticorruption Law is presented, resulting in the drawing of some conclusions on the subject.

Keywords: Compliance; Public Administration; Anti-corruption Law; Law of State Companies. 


\section{INTRODUÇÃO}

Escândalos são noticiados cotidianamente pela imprensa envolvendo atitudes antiéticas de agentes públicos. A administração ineficaz dos recursos estatais é agravada por atos de corrupção, e decorrência de relações não saudáveis entre indivíduos e o Estado.

A busca pela satisfação de interesses exclusivamente privados intensifica a corrupção, sendo, dessa maneira, o comportamento oposto aos deveres da função pública. Pela corrupção, os órgãos públicos são utilizados para enriquecimento pessoal ou favorecimento de terceiro.

Destaca-se que os princípios que regem a Administração Pública devem subordinar toda a gestão estatal. $\mathrm{O}$ atendimento a tais princípios contribui para uma administração com mais responsabilidade, assumindo um papel preventivo no planejamento de suas ações e na orientação de suas condutas, tendo como objetivo o cumprimento da finalidade pública a que se destina. No entanto, apesar de um ordenamento jurídico que positivou, em sua Carta Magna, diversos princípios de relevante importância ao combate de ilicitudes por agentes públicos, essa previsão constitucional ainda não foi suficiente para promover um ambiente íntegro, e que favoreça uma estrutura sólida contra a corrupção na Administração Pública brasileira.

Além do exposto, uma das motivações para a elaboração deste artigo se deu por ocasião da “Operação Lava Jato", pela qual diversos agentes da Petrobras foram condenados pela Justiça em decorrência de atos de desvio de recursos, sendo grande parte dos acusados integrantes de alto escalão da estatal petrolífera. No entanto, a estatal possuía um Código de Conduta desde o ano de 1998, o que demonstra que a mera existência de uma norma interna de Integridade não pode ser considerada suficiente para a prevenção de atos de corrupção.

Preliminarmente, associar o Compliance ${ }^{1}$ à Administração Pública pode soar um tanto incomum, haja vista que, teoricamente, esse instituto teria sido criado com o objetivo de adequar as sociedades privadas à conformidade legislativa vigente. Contudo, a realidade brasileira exige mudança comportamental ante os atos de corrupção, seja por parte das sociedades privadas bem como dos órgãos estatais.

Entendemos que quaisquer atos ou ações que tenham por objetivo a promoção do combate à corrupção sejam realmente efetivos. Porém, devemos sim refletir sobre os efeitos de uma cultura de Compliance na Administração Pública.

Uma cultura que valorize somente as normas necessita ser sopesada pela ideia de resultados, pelo princípio constitucional da eficiência, sob risco de um excesso de formalismo no âmbito público e seu eventual "engessamento" da atuação estatal.

A aplicação de um programa de integridade não deve fazer com que o Estado não atinja seus objetivos, ao negar benefícios unicamente por um acúmulo de procedimentos e regras. Portanto, apenas adotar uma cultura de Compliance, simplesmente com o intuito de criação de controles do cumprimento legal não parece ser suficiente para elevar o grau de eficiência do Estado - ou seja,

1 Este termo tem origem no verbo de língua inglesa to comply, que significa agir de acordo com uma regra, instrução ou comando, sendo mais bem aprofundado no item 4 do presente artigo. 
corre-se o risco de, com a adoção dessas práticas, tornar a atuação pública ainda mais burocrática, redundando, assim, em sérios entraves ao Estado.

A título de exemplo dessa aplicação do Compliance sem a necessária preocupação de sua efetividade, concebamos que um município da federação adquira um automóvel para atendimento de serviços hospitalares, seguindo, nesse processo de obtenção, todos os certames licitatórios existentes. Entretanto, depois de comprado, o respectivo automóvel fica guardado na garagem da Secretaria de Saúde, sem uso, pois não foram atendidas as demais regras trazidas pelo respectivo programa de Compliance do Estado. Cumpriu-se a lei, o município foi aderente, mas a finalidade do gasto, a efetividade, a economicidade, poderiam ser comprometidas mesmo assim².

Ademais, como assevera Edimur Ferreira de Faria (2019, p. 162-163), a população vem reiterando de maneira ordenada a sua insatisfação com a Administração estatal, exigindo políticas públicas que atuem no combate à corrupção, à improbidade administrativa, ao prejuízo ao erário, entre outras ações que sejam pautadas na transparência. Esse autor complementa que a concretização de preceitos fundamentais elencados na Constituição de 1988 somente será efetiva com a prática

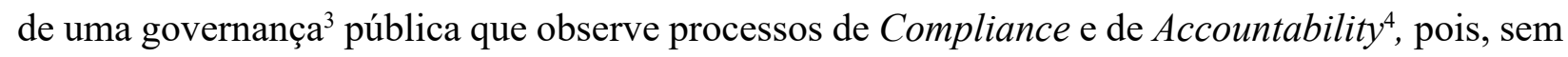
esses processos ou métodos de controle, a corrupção pode se alastrar.

Nessa lógica, o presente trabalho tem como um de seus principais desígnios a demonstração do crescimento das normas de integridade no ordenamento jurídico brasileiro, a análise da importância do Compliance face à realidade pátria e a efetiva aplicação do Compliance na Administração Pública. Para tanto, buscaremos compreender os efeitos do Compliance em nível internacional e nacional, mediante a análise de normas que prezam pela integridade de seus receptores. Ademais, passaremos pelo balanço de cinco anos da sanção da Lei Anticorrupção brasileira, uma das principais normas locais que abordam a temática.

\section{A CORRUPÇÃO E SEUS EFEITOS}

O autor do livro Corrupção: um estudo sobre poder político público e relações pessoais no Brasil, Marcos Otávio Bezerra, inicia sua obra questionando "Então o que é hoje a corrupção nesse país?" (BEZERRA, 1995). Essa pergunta foi realizada em entrevista publicada pelo Jornal do Brasil, em 24 de maio de 1992, ao empresário Emílio Odebrecht (BEZERRA, 1995). Em resposta, o empresário de uma das maiores empreiteiras do país, aponta:

Eu acho que a sociedade toda é corrompida e ela corrompe. Hoje para o sujeito resolver alguma coisa, até para sair de uma fila do INPS, encontra seus artifícios de amizade, de um presente, de um favor. Isso é considerado um processo de suborno. O suborno não é um problema de valor, é a relação estabelecida (BEZERRA, 1995, p. 11).

2 Vale destacar que a ineficiência contribui mais ainda para o desperdício de recursos públicos que a corrupção. Isto é, não que a corrupção não seja importante, mas, neste caso, são dois fatores: ineficiência e corrupção.

3 Aqui definido como a estrutura pelo qual as organizações dirigem e monitoram suas administrações.

4 Termo da língua inglesa que pode ser traduzido e entendido como prestação ou rendimento de contas, devendo ser realizada, preferencialmente, de modo tempestivo, compreensivo e ético. 
Ao analisar a declaração feita por Odebrecht, Bezerra extrai dois elementos. Primeiro, uma concepção da corrupção que, nesse caso, é confundida com a "amizade", o "presente", "o favor" e é entendida como a "relação estabelecida". Segundo, existe a indicação de alguns dos meios utilizados para a efetividade da corrupção. Os elementos como a "amizade", o "presente" e o "favor" são apontados como caminhos para a obtenção de certos benefícios. Além disso, a declaração parece apresentar também relações e mecanismos sociais concebidos como legítimos e que fazem parte do cotidiano dos brasileiros (BEZERRA, 1995, p. 11). ${ }^{5}$

Os autores citam inúmeras definições de corrupção ${ }^{6}$. No entanto, destacaremos aqui a definição feita por Klitgaard, qual seja:

Corrupção é o comportamento que se desvia dos deveres formais de uma função pública devido a interesses privados (pessoais, familiares, de grupo fechado) de natureza pecuniária ou para melhorar o status, ou que viola regras contra o exercício de certos tipos de comportamento ligados a interesses privados (KLITGAARD, 1994, p. 40).

Segundo a Organização para a Cooperação e Desenvolvimento Econômico (OCDE), os custos da corrupção para o desenvolvimento econômico, político e social são crescentemente evidentes (OECD, 2014, p. 1). Dessa forma, a corrupção atuaria na redução da eficiência do Estado e no aumento da desigualdade social em números relevantes: em um ano, 2,6 trilhões de dólares seriam gastos em corrupção, sendo um trilhão destinado exclusivamente ao pagamento de subornos. Vale ressaltar que o primeiro montante equivale a 5\% do Produto Interno Bruto global. ${ }^{7}$

Angel Gurría, Secretário-Geral da OCDE, aponta que a corrupção atua em todos os países e níveis da sociedade, distorcendo as intenções econômicas e sociais, reduzindo a eficiência e aumentando a desigualdade. Gurría ainda aponta que três são as consequências danosas da corrupção: o custo de fazer negócios aumentaria, recursos públicos seriam desperdiçados e os pobres seriam colocados de lado (OECD, 2014).

\footnotetext{
5 Primeiro, uma concepção da corrupção. Neste caso, ela é confundida com a "amizade", o "presente" e o favor' e é fundamentalmente entendida como a "relação estabelecida". Segundo, há na explicação uma indicação de meios pelos quais a corrupção se efetua. A "amizade", o "presente", e o "favor" são apontados como "artifícios" corruptores, caminhos para a obtenção de benefícios. A passagem parece apresentar também um paradoxo, relações e mecanismos sociais concebidos como legítimos, que fazem parte da vida cotidiana das pessoas - como as relações de amizade e a troca de presentes e favores - são associados e confundidos com a corrupção - algo publicamente denunciado como ilícito e ilegítimo (BEZERRA, 1995, p. 11).

6 Não obstante as inúmeras definições acerca de "corrupção", cabe destacar também a definição encontrada no Código Penal pátrio, onde, segundo Art. 317, temos previsão de Corrupção Passiva sendo "Solicitar ou receber, para si ou para outrem, direta ou indiretamente, ainda que fora da função ou antes de assumi-la, mas em razão dela, vantagem indevida, ou aceitar promessa de tal vantagem", e, conforme Art. 333 do mesmo diploma legal, a Corrupção Ativa, definida como "Oferecer ou prometer vantagem indevida a funcionário público, para determiná-lo a praticar, omitir ou retardar ato de oficio".

7 Os dados considerados para a realização desta estimativa não foram revelados publicamente pela OCDE.
} 


\section{O COMPLIANCE EM NÍVEL INTERNACIONAL}

A discussão internacional a respeito do Compliance ocorre com bastante intensidade ao longo dos recentes anos nas organizações internacionais, o que acaba por influenciar, direta ou indiretamente Estados a aderirem aos mesmos princípios e regulações adotadas por aquelas. Por meio da percepção dos efeitos negativos da corrupção, houve a priorização do tema na esfera internacional e diversos acordos foram firmados para preveni-la e combatê-la. Desde o final da década de 90, foi desenvolvida uma estrutura jurídica internacional para combater a corrupção. Nessa estrutura, as convenções têm papel de destaque dada a sua importância para a criação de padrões internacionais na luta contra a corrupção.

Nessa perspectiva a nível global, temos a Convenção sobre o Combate da Corrupção de Funcionários Públicos Estrangeiros em Transações Comerciais Internacionais (Convenção OCDE), de 1997; e a Convenção das Nações Unidas contra Corrupção (Convenção da ONU), de 2005. Em aspectos regionais, foram instituídas a Convenção Interamericana contra a Corrupção (Convenção da Organização dos Estados Americanos - OEA), de 1996; a Convenção Penal sobre a Corrupção, de 1998, e a Convenção Civil sobre a Corrupção, de 1999, do Conselho da Europa; a Convenção relativa à Proteção dos Interesses Financeiros das Comunidades Europeias, de 1995, e a Convenção relativa à Proteção dos Interesses Financeiros das Comunidades Europeias, de 1995, e a Convenção relativa à Luta contra a Corrupção em que Estejam Implicados Funcionários das Comunidades Europeias ou dos Estados-Membros da União Europeia, de 1997; e a Convenção da União Africana sobre a Prevenção e o Combate à Corrupção de 2003.

As convenções variam no que diz respeito ao seu escopo (regional ou global) e aos tipos de obrigações assumidas, compromissos políticos abrangentes ou recomendações específicas com previsão de processos de revisão. Porém, identifica-se a finalidade comum dos instrumentos: (i) dar destaque político à luta contra a corrupção; (ii) estabelecer normas e princípios legalmente vinculantes pelos quais os Estados signatários podem ser responsabilizados; e (iii) promover a ação interna e a cooperação internacional necessárias para enfrentar as muitas facetas da corrupção (OCDE, 2014).

O Brasil, que é um dos Estados-Partes da ONU, ratificou convenções que requerem a responsabilização de pessoas jurídicas por corrupção, o que mais tarde impulsionaria a publicação da Lei Anticorrupção brasileira. A Convenção das Nações Unidas Contra a Corrupção, adotada pela Assembleia-Geral das Nações Unidas em 31 de outubro de 2003 foi ratificada pelo Brasil por meio do Decreto n. 5.687/06. A finalidade da presente Convenção é promover e fortalecer medidas para a prevenção e combate mais eficaz e eficiente da corrupção; promover, facilitar e apoiar a cooperação internacional e a assistência técnica na prevenção e na luta contra a corrupção, incluída a recuperação de ativos; e promover a integridade, a obrigação de render contas (rendimento de contas é a expressão análoga para Accountability ou transparência e integridade) e a devida gestão dos assuntos e dos bens públicos.

Ademais, a Convenção Interamericana contra a Corrupção, de 29 de março de 1996, foi 
ratificada pelo Brasil por meio do Decreto n. 4.410/02. Os propósitos da Convenção são: promover e fortalecer o desenvolvimento, por cada um dos Estados-Partes, dos mecanismos necessários para prevenir, detectar e punir e erradicar a corrupção; e promover, facilitar e regular a cooperação entre os Estados-Partes a fim de assegurar a eficácia das medidas e ações adotadas para prevenir, detectar, punir e erradicar a corrupção no exercício das funções públicas, bem como os atos de corrupção especificamente vinculados a seu exercício.

A existência de Códigos de Conduta e Governança Corporativa também figura como uma recomendação da OCDE para as empresas de propriedade estatal (State Owned Enterprises $S O E$ ), bem como a adoção de práticas que evitem a ocorrência de atos de corrupção, fundamentais para o desenvolvimento do empreendimento estatal. Apesar de ampla participação no cenário internacional de combate à corrupção, o Brasil não ofuscou a imagem de uma nação corrupta e muito menos conseguiu desvencilhar-se de escândalos ligados a ilegalidades públicas. Assim sendo, as normas de integridade foram, progressivamente, positivadas no arcabouço jurídico brasileiro com a finalidade de coibir os atos de corrupção existentes.

\subsection{FCPA - Foreign Corrupt Practices Act e Bribery Act}

As regras da FCPA (Foreign Corrupt Practices Act) e do Bribery Act objetivam essencialmente o combate à corrupção em seus respectivos países. O norte-americano FCPA iniciou o tema no mundo empresarial e inspirou a legislação britânica culminando na formação do Bribery Act.

No ano de 1977, foi promulgada nos Estados Unidos a FCPA com o intuito de proibir a corrupção de agentes públicos e governamentais estrangeiros que teriam por finalidade obter, reter ou direcionar uma transação comercial. A justificativa da aprovação da referida lei foi a seguinte:

As investigações feitas por volta da metade dos anos setenta pela Security and Exchange Commission revelaram que mais de 400 empresas norte-americanas admitiram ter feitos pagamentos questionáveis ou ilegais e os montantes foram superiores a US\$ 300 milhões de dólares. Os atos variaram desde suborno a autoridades estrangeiras de alto nível, com o objetivo de garantir algum tipo de decisão favorável por parte do Governo do país a que pertencia tal autoridade até a prática dos assim chamados "pagamentos facilitadores"; estes foram feitos, segundo alegações, para conseguir com que os funcionários públicos (de países estrangeiros) efetivamente cumprissem seus deveres legais ou regulamentares (MOREIRA, 2002, p. 64).

O regramento se aplica potencialmente para qualquer indivíduo, empresa, conselheiro, diretor, funcionário ou agente de uma sociedade e qualquer acionista, agindo em nome de uma empresa, que será fiscalizado pelo Departamento de Justiça Americano e coordenado pelo Securities and Exchange Commission - SEC (COIMBRA; MANZI, 2010, p. 44). Contudo, devido a certas alterações no ano de 1988, que foram projetadas para implementar a Convenção Anti-suborno da 
OCDE, as disposições anticorrupção também são aplicáveis as empresas estrangeiras e pessoas físicas que causem, direta ou através de agentes, um ato de promoção de pagamento de corrupção que ocorra além do território americano (CUNHA; EL KALAY, 2019, p. 21).

O Bribery Act de 8 de abril de 2010 foi promulgado durante a gestão de Kenneth Clarke, então secretário do Departamento de Justiça do Reino Unido e entrou em vigor em $1^{\circ}$ de julho de 2011. Conforme dito anteriormente, a regulamentação britânica teve influências do FCPA, porém realizou certas reformas na condução do assunto pelo Governo. Incluindo a abrangência do tema pelas autoridades quando os atos corruptos forem praticados no exterior. A questão da jurisdição extraterritorial foi ampliada, pois passou a abranger toda e qualquer empresa que faça transações com algum grupo do Reino Unido, independentemente de ser dentro de seu território ou não.

Deste modo, o Bribery Act abrange o conceito dos responsáveis pelos atos corruptos atingindo toda a cadeia fornecedora do produto ou da prestação de serviços da companhia. Assim, uma empresa brasileira que produz determinado produto para outra sociedade e que, por sua vez, fornece esse produto para uma outra empresa no Reino Unido, poderá ser igualmente penalizada.

Por essa razão, sociedades de economia mista, empresas públicas e demais entes estatais também devem observar o que preconizam esses diplomas estrangeiros e preocuparem-se em conhecer progressivamente o histórico e procedência das empresas com quem possuem relações comerciais, devendo, inclusive, abranger esses tópicos contratualmente para que lhes sirvam de matéria de prova em possíveis ações de regresso.

Finalmente, resta evidente a crescente demanda de adequação a padrões internacionais visando à adaptação das relações internacionais e prevendo penalidades por atos de corrupção a nível global. Logo, alegar falta de conhecimento não é algo cabível, pois as legislações supracitadas punem, inclusive, a omissão pela fiscalização do histórico da empresa com que se mantêm relações.

\section{A REALIDADE BRASILEIRA}

Apesar da impossibilidade de se realizar um cálculo exato do custo da corrupção, é consenso que se trata uma quantia exorbitante. A Federação das Indústrias do Estado de São Paulo (FIESP), em seu estudo datado de março de 2010 sobre o custo da corrupção no Brasil, considerando o índice de percepção da corrupção da Transparency International, projetou que de 1,38\% a 2,3\% do PIB brasileiro são perdidos por ano com essa prática (FIESP, 2012).

Para chegar a essa projeção, parte-se do pressuposto que se o Brasil possui um nível de percepção da corrupção ${ }^{8}$ igual à média desses países de 7,45, o produto per capita do país seria de US\$ 9.184, montante bem diferente dos US\$ 7.954 existentes à época. Essa elevação representaria

8 A corrupção é medida por sua "percepção", haja vista que os atos corruptos, em geral, são deliberadamente escondidos do público, tornando-se conhecidos apenas por meio de investigações e divulgação de escândalos. A Transparência Internacional argumenta que estatísticas empíricas exatas, como o número de denúncias de suborno, ou o número de casos de corrupção levados à justiça, não refletem necessariamente o nível de corrupção de um país. Por isso, a ONG resolveu criar um índice focado na experiência de pessoas que estão diretamente envolvidas com o setor público de todos os países, como empresários, experts do sistema político de cada país e a população em geral. O Índice é construído a partir de doze fontes diferentes, que incluem o Banco Mundial e o Fórum Econômico Mundial. 
um aumento de $15,5 \%$ na média do período de 1990 a 2008, correspondendo a um custo médio anual de corrupção estimado em 41,5 bilhões de reais, sendo 1,38\% do PIB (dados de 2008), o que, por conseguinte, prejudica o aumento da renda per capita ${ }^{9}$, compromete o crescimento e a competitividade do país, além de reduzir a possibilidade de oferecer melhores condições econômicas e de bem-estar social à população (FIESP, 2012).

É evidente que não há como garantir que o administrador público reverteria tais montantes em benefício do bem-estar social, no entanto, fato é que os valores despendidos com a corrupção reduzem a possibilidade de assegurar o exercício dos direitos sociais e individuais, conforme preâmbulo da Constituição da República Federativa do Brasil de 1988.

Adicionalmente a esses dados, a Operação Lava Jato, que desvendou um dos maiores esquemas de corrupção do país nos últimos tempos, já estima que o prejuízo para o país extrapole a ordem de R 140 bilhões de reais.

Aspirando ao combate à corrupção, o Estado brasileiro ratificou a Convenção das Nações Unidas contra a Corrupção (ONU, 2005), a Convenção Interamericana de Combate à Corrupção (OEA, 2002) e a Convenção sobre o Combate à Corrupção de Funcionários Públicos Estrangeiros em Transações Comerciais Internacionais da Organização para a Cooperação e Desenvolvimento Econômico (OCDE, 2000). Porém, o grande marco legislativo ocorre somente com a Lei Anticorrupção Brasileira (Lei n. 12.846/13), tendo em vista que estabeleceu um conceito aberto de Pessoa Jurídica para fins de responsabilização, o qual abrange entes da Administração Pública e estabeleceu um princípio de moralidade administrativa renovado, vinculado às regras de Compliance da boa gestão empresarial internalizadas no setor público.

\section{O COMPLIANCE}

O termo Compliance tem origem no verbo de língua inglesa to comply, que significa agir de acordo com uma regra, instrução ou comando. O Compliance é uma medida antiga de combate à corrupção, previsto há muito tempo na legislação estrangeira, especialmente no norte-americano Foreign Corrupt Practices Act of 1977 e no britânico Bribery Act 2010.

Seu surgimento se dá por intermédio da legislação norte-americana, com a criação da Prudential Securities, em 1950, e com a regulação da Securities Exchange Commission (SEC), de 1960, quando se fez menção à necessidade da institucionalização dos programas de Compliance com a finalidade de criar procedimentos internos de controle e monitoramento das operações entre pessoas. Posteriormente, no ano de 1977, registrou-se na Europa a Convenção Relativa à Obrigação de Diligência dos Bancos no Marco da Associação de Bancos Suíços, instituindo bases de um sistema de autorregulação de conduta, vinculando as instituições, cujo descumprimento resultaria na aplicação de sanções como multas e outras penalidades. Haja vista que não possui tradução exata em idioma português, esse termo estrangeiro pode significar conformidade, observância

9 Cabe destacar que, haja vista o entendimento da FIESP, a rigor, o cálculo da renda per capita não é afetado diretamente pelos valores pagos a título de corrupção, pois o PIB engloba o consumo e os investimentos privados feitos pelos corruptos passivos. 
ou cumprimento. Porém, esses vocábulos não exprimem com exatidão o pleno conceito de Compliance, motivo pelo qual a maioria dos autores brasileiros prefere utilizar o termo em sua versão alóctone.

Partindo do pressuposto que Compliance é encontrar-se em conformidade com diretrizes, regulamentos internos e externos, esse termo visa ainda ao cumprimento de costumes, princípios e que compõem toda a estrutura de uma entidade, seja pública ou privada.

Historicamente, nunca houve grande preocupação a respeito do Compliance no Brasil. No entanto, em junho de 2013, a população brasileira foi às ruas reivindicando medidas que coibissem os diversos escândalos políticos que foram trazidos à tona nos últimos tempos.

A Controladoria Geral da União (CGU), em 18 de fevereiro de 2010, propôs o Projeto de Lei n. 6.826/2010 e que foi aprovado na Câmara dos Deputados em maio de 2011. Todavia, encontrava-se paralisado no Senado. Somente após inúmeros e intensos protestos, em 2013, é que se obteve regime de tramitação de prioridade e foi aprovado em 05 de julho de 2013, sendo transformado na Lei Ordinária n. ${ }^{\circ}$ 12.846/2013 em 02 de agosto de 2013, que ficou então conhecida como "Lei Anticorrupção" brasileira.

Além de atender aos ditames da Lei Anticorrupção, foram promulgadas recentemente algumas normas de caráter ético e envoltas em medidas de Compliance. A Controladoria Geral da União, mesmo que não seja uma entidade específica na aplicação de temas de Compliance, conduz as recomendações pela implementação de programas de Compliance e, além disso, em 2015, a CGU publicou um guia de integridade de modo a auxiliar instituições privadas e empresários a como se portarem diante de problemas relacionados à corrupção e suborno. Em 2017, publica um guia de como as instituições privadas devem aplicar o Compliance em sua interação com organismos públicos. Ademais, destaca-se a ação indutora do Tribunal de Contas da União (TCU) visando à melhoria da gestão de Compliance na Administração Federal, especialmente das estatais, no ano de 2014.

A Convenção das Nações Unidas contra a Corrupção, ratificada pelo Brasil por meio do Decreto n. 5.687/06, uma das normas precursoras em nosso sistema jurídico a tratar dessa temática, já apontava a necessidade da implementação de um programa de gestão pública para assuntos como integridade e transparência. Essa mesma disposição expressa acerca da implementação de Códigos de Conduta para servidores públicos, que visa a combater preventivamente a corrupção, por meio do desenvolvimento institucional de princípios relacionados à integridade, à honestidade e à responsabilidade do agente estatal.

Pelo Decreto Federal n. 9.203/2017 ${ }^{10}$ estabeleceu-se a obrigatoriedade de instituição de programas de integridade para órgãos públicos e entidades da Administração indireta, autárquica e fundacional da União Federal e, no dia posterior à data deste Decreto, foi encaminhado ao Congresso o Projeto de Lei n. 9.163/2017, que trata da mesma temática. Esses programas de integridade devem ter o objetivo de promover a adoção de medidas e ações institucionais destinadas

10 Importante mencionar que o referido Decreto foi concebido a partir de um estudo de cinco anos de duração realizado pelo Tribunal de Contas da União (BRASIL, 2017). 
à prevenção, à detecção, à punição e à remediação de fraudes e atos de corrupção, segundo o art. 19 do Decreto Federal n. 9.203/2017¹, e serão estruturados com base no comprometimento e apoio da alta administração, da existência de unidade responsável pela implementação no órgão ou na entidade, da análise, avaliação e gestão dos riscos associados ao tema da integridade e do monitoramento contínuo dos atributos do programa de integridade.

Percebemos também que o Compliance ganha importância dentro do estado do Rio de Janeiro, bem como no Distrito Federal. Por meio da Lei estadual n. 7.753/2017, passou-se a exigir a implementação de Programas de Compliance de empresários que celebrem certos contratos ou convênios com o estado fluminense. Já o DF promulgou a Lei distrital n. 6.112/2018 que dispõe a obrigatoriedade da implantação de Programas de Integridade para empresários que contratarem com a Administração Pública do Distrito Federal. Mais recentemente, podemos também citar a Portaria n. 1.089/2018, da Controladoria-Geral da União, que estabelece procedimentos para estruturação, execução e monitoramento de programas de integridade em cerca de 350 órgãos e entidades do Governo Federal.

Por fim, conforme denota Victor Hugo Alcalde do Nascimento (2019, p. 52), o estado do Compliance contemporâneo encontra-se em fragmentação e utopia:

De um lado, convivem normas oriundas de diferentes entes legiferantes e que reclamam o cumprimento pela pessoa jurídica, assim como, proliferam as regulamentações empresariais que se revelam verdadeiras codificações privadas. Essas codificações significam, a final, que entes privados adquiriram a capacidade de "legislar", ou seja, de criar regras que prescrevem determinados comportamentos. O resultado é o estabelecimento de uma instância paralela, um "poder" concorrente ao Judiciário, ao Legislativo, e, à própria Administração Pública, capaz de estatuir punições para aqueles funcionários que violam seu mandamento. A ordem jurídica é, portanto, fragmentada (NASCIMENTO, 2019, p. 52).

Neste sentido, com a aplicação de programas de Compliance e de códigos de ética e conduta dentro das instituições (que a seguir trataremos com mais profundidade), temos uma nova forma de "legislar", podendo, ainda, estatuir punições para os funcionários que estiverem agindo de modo contrário ao que preceituam os referidos programas.

\section{A ATUAÇÃO DO COMPLIANCE NO SETOR PRIVADO}

Uma empresa não poderá se abster de analisar adequadamente qual a melhor decisão a ser tomada para determinada situação, devendo conduzir suas operações dentro dos mais altos padrões

11 Art. 19. Os órgãos e as entidades da administração direta, autárquica e fundacional instituirão programa de integridade, com o objetivo de promover a adoção de medidas e ações institucionais destinadas à prevenção, à detecção, à punição e à remediação de fraudes e atos de corrupção, estruturado nos seguintes eixos: I - comprometimento e apoio da alta administração; II - existência de unidade responsável pela implementação no órgão ou na entidade; III - análise, avaliação e gestão dos riscos associados ao tema da integridade; e IV - monitoramento contínuo dos atributos do programa de integridade. 
éticos, além de evitar ocorrências de corrupção e suborno, ao mesmo tempo em que fomenta uma cultura de anticorrupção. Ademais, a Lei n. 6.404/76 prevê, especificamente nos Arts. 153 a 160, alguns deveres e responsabilidades dos administradores das companhias, dentro os quais vale destacar o disposto no Art. 153 onde resta mencionado que o administrador deve empregar, no exercício de suas funções, o cuidado e diligência que todo homem ativo e probo costuma empregar na administração de seus negócios ${ }^{12}$.

Com a finalidade de implementar essa nova cultura, uma empresa que realmente queira seguir padrões éticos deve abster-se de oferecer ou receber benefícios (presentes, entretenimento, hospitalidade etc.) ou até mesmo pecúnia, para fins políticos ou beneficentes para qualquer parceiro de negócios - seja pessoa física ou jurídica - que envolvam ou que simplesmente pareçam envolver qualquer tipo de suborno ou outro tipo de propósito inadequado.

Evidentemente, no meio empresarial, existe a prática de oferecimento de brindes ou convites para eventos técnicos ou lazer (conhecido por marketing de relacionamento), no entanto, essa não deve ser excessiva ou extravagante, sempre respeitando o limiar razoável e permitido pela política interna de uma sociedade empresária.

Existem ainda casos em que, por razões culturais, funcionários recebem presentes e uma eventual recusa causaria ampla indisposição entre as partes que estariam muito próximas da consolidação de um acordo comercial. Nesses casos, o recebimento de um presente deve ser notificado assim que possível ao Compliance Officer (geralmente o cargo do funcionário responsável por zelar pelo Compliance na empresa) ou, não havendo essa figura, para o Diretor de Recursos Humanos, Diretor de Compras ou semelhantes.

Outro ato que não pode ocorrer dentro de uma instituição privada que estima por normas de integridade é a realização de pagamento a funcionários públicos tendentes a garantir ou apressar ações governamentais rotineiras, legais e não discricionárias. Tais pagamentos devem ser sumariamente proibidos, mesmo que esses atos sejam considerados costumeiros na jurisdição local ${ }^{13}$.

Doações também devem ser consideradas um alerta à instituição privada. Por vezes, essas doações podem possuir uma finalidade social ou beneficente, porém poderá restar comprovada a caracterização de um suborno ou corrupção. Isso é, se uma entidade governamental, agente público ou o familiar de um agente público se beneficiar, direta ou indiretamente, de uma doação para fins beneficentes, poderá configurar-se facilitação indevida ou "troca de favores".

A empresa deverá estabelecer um Canal de Denúncias ou um Portal de Comunicações possibilitará que um funcionário que suspeite ou receba uma oferta de suborno ou corrupção possa comunicar-se, respeitando-se seu sigilo e que a eventual denúncia possa ser efetivamente investigada internamente e, em sendo comprovada, ocasione a aplicação de sanções aos envolvidos.

12 Art. 153. O administrador da companhia deve empregar, no exercício de suas funções, o cuidado e diligência que todo homem ativo e probo costuma empregar na administração dos seus próprios negócios.

13 Conforme anteriormente descrito, no contexto brasileiro, estas ações poderiam ensejar nos crimes de Corrupção Passiva e/ou Corrupção Ativa, dispostos nos Arts. 317 e 333 do Código Penal. 


\subsection{Pilares do Compliance}

Tendo em vista a publicação de normas de integridade no ordenamento jurídico brasileiro e os diversos escândalos amplamente veiculados pelos meios de comunicação, muitas empresas adequam suas condutas por meio do Compliance.

Visando à melhor orientação para a aplicação de um programa de conformidade, especialistas elaboraram certos "pilares de um programa de Compliance". Esses, ainda que genéricos e mutáveis, sempre a depender de quem os indica, servirão para direcionar um programa de Compliance mais eficaz. $^{14}$

Um programa de Compliance eficaz deve ser construído sobre uma fundação sólida de valores éticos. Dessa forma, primeiramente, será necessário o suporte da alta administração, sendo esse suporte um ingrediente essencial para a devida implementação do programa. Essa alta administração deve apoiar e se envolver no planejamento e na execução das ações. No entanto, não basta apenas a existência de padrões exigidos pela alta administração. Para possibilitar a plena implementação e funcionamento do Compliance em uma instituição, é fundamental que existam indivíduos dedicados ao tema, eles são conhecidos como Compliance Officers. Esses indivíduos devem ser revestidos de autoridade e devem possuir recursos suficientes, e com suficiente autonomia de gestão, para garantir que o programa seja eficaz para prevenir, detectar e punir condutas empresariais antiéticas.

A avaliação de riscos é altamente relevante em um programa de conformidade. Riscos são eventos potenciais, não certos. Dessa forma, é necessário que se conheçam os objetivos de uma instituição para que, a seguir, se possam construir códigos de conduta, políticas e monitoramentos sob esses objetivos e riscos apresentados por eles. Ademais, a fim de tornar a condução de uma análise de riscos eficiente, devem ocorrer planejamentos, entrevistas, análises de documentações e catalogação de dados e estabelecimento de medidas de remedição. Além disso, é crucial que a instituição conheça o risco dos negócios e leis aplicáveis à região e ao setor econômico em que atua.

Após a avaliação dos riscos e prévio conhecimento das normas aplicáveis às suas operações, faz-se necessária a criação de Códigos de Conduta e Políticas de Compliance, que servirão como a formalização da postura adotada por uma instituição acerca de diversos assuntos, guiando os integrantes desta instituição para práticas éticas e legais na condução de suas atividades. Esses registros devem abordar (incluindo, mas não se limitando a) temas de antitruste, anticorrupção, lavagem de dinheiro, controles de exportação e sanções, Due Diligence ${ }^{15}$ sobre representantes legais de terceiros, parceiros e fornecedores, bem como brindes, refeições e entretenimento, interações com funcionários públicos nacionais e estrangeiros, despesas de viagem. Vale ressaltar

14 Os apontamentos aqui realizados será uma análise da publicação Infográfico: os 9 pilares de um programa de compliance (SANTOS, 2017), bem como da publicação 5 essential elements of Compliance, 2018.

15 Traduzida como devida diligência ou diligência prévia, refere-se, no Brasil, ao processo de investigação de uma oportunidade de negócio que o investidor deverá aceitar para poder avaliar os riscos de uma transação comercial. Embora tal investigação possa ser feita por obrigação legal, o termo refere-se normalmente a investigações voluntárias. Um exemplo de diligência prévia é o processo pelo qual um potencial adquirente avalia o seu alvo e respectivos ativos, quando tem a intenção de fazer uma aquisição (BRASIL, 2018a). 
que a criação desses documentos servirá, também, para evidenciar o compromisso da entidade em eventuais discussões sobre a efetividade de um programa de Compliance.

Uma empresa preocupada com a aplicação concreta do Compliance deve possuir controles internos para assegurar que os riscos sejam minimizados, tanto no nível interno quanto no externo. Registros contábeis e financeiros podem ser utilizados para transparecer a realidade do negócio. Além do mais, a empresa deve ter bastante claro o estabelecimento de protolocos e procedimentos para, mais uma vez, evitar que sejam apenas controles pro forma.

Com o propósito de fazer do Compliance uma cultura organizacional daquela instituição, será necessária a realização de treinamentos e comunicações aos seus funcionários. Além da adesão da alta administração, os colaboradores também necessitam entender os objetivos, regras e sua adequação naquele programa para a sua efetiva concretização. Destaca-se que, se possível, é extremamente significativa a execução de treinamentos e comunicações a terceiros que se relacionem com determinada empresa.

Canais de denúncia deverão fazer parte do programa de Compliance. Um sistema de denúncia eficaz deve incluir a garantia da proteção ao denunciante de boa-fé, por exemplo, a não retaliação e o recebimento de denúncias anônimas é fundamental implementar protocolos que possam lidar com a informação adequadamente.

Em havendo uma denúncia no respectivo canal, a empresa precisa investigar quaisquer indícios de comportamentos antiéticos e ilícitos que tenham sido noticiados. Em seguida, devemse tomar as providências necessárias, com as devidas correções e, conforme o caso, sanções.

O programa de Compliance não pode somente restringir-se ao comportamento da organização. Desta feita, deve haver a previsão de uma Due Diligence em fornecedores, representantes, distribuidores e demais parceiros. Isso é, será importante a avaliação do histórico de cada um desses como condição para ao estabelecimento de uma relação comercial.

Em conclusão, como último dos pilares, será fundamental a auditoria e o monitoramento do programa de conformidade. Esse monitoramento deve ser contínuo, avaliando sua aplicação e sua execução pelos sujeitos, além da averiguação de que todo o citado neste capítulo vem sendo verdadeiramente efetuado. Isso permitirá que haja evoluções e alterações ao longo do andamento do programa de Compliance.

\section{A APLICAÇÃO DO COMPLIANCE NO ORDENAMENTO JURÍDICO BRASILEIRO}

O ordenamento jurídico brasileiro, por meio da Lei Anticorrupção, indica que as empresas do setor privado adotem o chamado Programa de Integridade (ou Compliance) de acordo com o artigo 41 do Decreto n. 8.420/15. Dessa forma, a finalidade está destinada diretamente à evitabilidade de práticas corruptas contra a Administração Pública, seja nacional ou estrangeira. Como acima citado, em alguns estados pátrios, instituições privadas devem possuir programas de Compliance para concorrem a certames licitatórios, a fim de que seja possível atestar o controle dos riscos de sua gestão - funcionam como verdadeiros mecanismos de credibilidade e transparência, de modo 
a proteger o interesse público pela contratação de empresas idôneas.

Por meio do Decreto n. 5.687/06, em seu artigo $5^{\circ}$, já se fazia referência à instituição de um programa de gestão pública para assuntos que digam respeito a temas como: bem público, integridade, transparência e controle das contas públicas. Nesse mesmo diploma, em seu artigo $8^{\circ}$, existe clara disposição acerca da implementação de Códigos de Conduta para servidores públicos que se propõem ao combate preventivo à corrupção, por meio do desenvolvimento institucional de princípios relacionados à integridade, à honestidade e à responsabilidade.

A aplicação de programas de Compliance de natureza pública é um desafio. Escreveu Hely Lopes Meirelles: “[...] na Administração Pública não há liberdade nem vontade pessoal. Enquanto na administração particular é lícito fazer tudo que a lei não proíbe, na Administração Pública só é permitido fazer o que a lei autoriza." (MEIRELLES, 2008, p. 89). Dessa forma, para que um programa seja efetivo, deverá se adequar à realidade estatal e não apenas replicar conceitos e procedimentos que são aplicados em instituições privadas. Outro aspecto importante que deverá ser observado é a educação efetiva do gestor público, com treinamentos intensificados nas mudanças de cultura e de boa governança.

Exemplo dessa aplicação é a Legge Anticorruzione n. 190/2012 (Lei Anticorrupção da Itália) que, seguindo as orientações das Convenções Internacionais, ingressa na seara pública no sentido de prevenir a corrupção por meio do modelo de autorregulação da Administração Pública. Assim como ocorre no Compliance privado, o modelo do programa está nas ações preventivas disciplinadas por códigos de conduta específicos por parte dos agentes. Resumindo, o código ético será customizado para cada setor da Administração, levando em conta suas particularidades, sendo indispensável que os próprios servidores possam participar diretamente de sua elaboração. Pretende-se, consequentemente, levar a prevenção de atos de corrupção de maneira mais efetiva, evitando-se a inutilidade de códigos e estatutos genéricos ${ }^{16}$.

Nesta perspectiva, Camila Rodrigues Forigo (2019, p. 27-28) dispõe que é fundamental que cada esfera da Administração Pública tenha um sistema de controle diferenciado conforme seu tamanho, estrutura, atividade e riscos, considerando que dentro da própria Administração Pública há setores mais sensíveis à corrupção do que outros, ou seja, aqueles setores destinados a procedimentos de licitação e contratação com a iniciativa privada possuem mais fatores de risco de corrupção do que aquelas esferas destinadas ao atendimento à população carente, por exemplo.

Ademais, a Lei Anticorrupção italiana orienta que o Estado deve investir num plano trienal anticorrupção, o que evidenciaria a necessidade de planejamento contínuo das ações versando sobre a proteção do Estado. Entre as orientações para o plano de cumprimento estão: identificar nas atividades públicas quais os setores com elevado risco de corrupção; estabelecer regras e

16 Atualmente, algumas empresas do setor privado elaboram códigos genéricos de conduta, apenas para cumprirem com o disposto na Lei Anticorrupção brasileira. O mesmo código é aplicado para pessoas que trabalham na parte comercial (e que por vezes tratam diretamente com agentes estatais) e, por exemplo, para pessoas encarregadas de trabalhar somente com a manutenção de computadores. Sendo assim, códigos que tratem especificamente do contato com agentes públicos ou como se portar em uma reunião com concorrentes e, dessa forma, sendo mais aprofundados para uma pessoa da área comercial, serão muito mais efetivos do que códigos feitos genericamente e que se aplicam a todas as funções numa organização. Assim sendo, caso os próprios agentes possam participar da elaboração do código de conduta, os objetivos poderão ser atingidos de forma ainda mais assertiva. 
desenvolver atividades nas quais identificarem-se riscos de corrupção e criar mecanismos de controle preventivo; criação de mecanismos de supervisão constante sobre os programas que devam ser implantados no setor público, indicando claramente qual o modo de supervisão de atividades com risco corruptivo.

O agente estatal deve realizar atos de acordo com os princípios constitucionais e deve haver um controle destes atos ${ }^{17}$. O controle poderá ser efetuado pela própria Administração, dentro de seu dever de apurar e punir todos os atos ilegais ou abusivos praticados pelos agentes públicos, com base em regras estatutárias (no âmbito federal, a Lei n. 8.112/90, Estatuto do Servidor Público, em especial seu art. 116, inciso IX). Entretanto, por não demonstrarem a efetividade necessária (tendo em vista os escândalos circulados pela mídia) o Compliance e o ingresso de um programa de integridade específico, que não apenas identifique as atividades que gerem atos de corrupção, mas que introduza maneiras de se gerirem riscos e, de alguma forma, mitigá-los - poderá ser um caminho para demonstrar a integridade na Administração Pública e expectativas da sociedade em relação ao exercício de sua função.

Vale ressaltar que, conforme assinalam Vanice Regina Lírio do Valle e Marcelo Pereira dos Santos (2019, p. 172), a boa técnica de governar não é suficiente para garantir a consolidação dos princípios do Estado democrático de Direito, senão alinhada à moralidade e à legitimidade das escolhas públicas. Assim, de nada servirá o emprego da governança e do Compliance na Administração Direta e Indireta se os detentores das funções primordiais dos Estado continuarem adotando posturas pragmáticas e pseudoéticas, a fim de justificar suas atitudes.

Ademais, para Eduardo Saad-Diniz (2018, p. 36), no atual cenário brasileiro, a inteligência de Compliance favorece planejamento mais rigoroso para se antecipar a reações imprevisíveis de fiscalizadores e reguladores, que a qualquer momento podem vincular empresas ou dirigentes por informações colhidas em investigações, colaborações premiadas ou acordos de leniência.

\subsection{LeI ANTICORRUPÇÃo BraSILEIRA}

A Lei n. 12.846 de 2013, conhecida popularmente como a Lei Anticorrupção brasileira sanou uma lacuna existente no sistema jurídico pátrio sobre a responsabilização administrativa e civil de pessoas jurídicas que praticam atos ilícitos em desfavor da Administração Pública nacional e estrangeira, principalmente, atos de corrupção e fraude em licitações e contratos administrativos.

Inicialmente, destaca-se que, mesmo antes da vigência da Lei Anticorrupção, já era possível a responsabilização de empresas em irregularidades. Entretanto, as sanções previstas eram um tanto limitadas, em regra, à impossibilidade de a empresa envolvida ou beneficiada por ato de corrupção

17 Podemos citar como exemplos deste controle, o Código de Ética Profissional do Servidor Público Civil do Poder Executivo Federal (Decreto n. 1.171/94) que realiza o controle administrativo interno. A Controladoria Geral da União também o faz através de seu controle interno. O Ministério Público e o Tribunal de Contas da União também são agentes importantes de controle de gestão administrativa. O MP os realiza por meio de controle judicial, após provocação, via Lei de Improbidade Administrativa (Lei n. 8.429/92). Já o TCU efetiva o controle externo instrumentalizado via Art. 71 da Constituição Federal, bem como da Lei n. 8.443/92. 
licitar e contratar com a Administração, conforme previsto na Lei n. 8.666/93 (Lei das Licitações) e na Lei n. 10.520/02 (Lei do Pregão); ou dependiam da existência de elementos relativos à culpabilidade dos agentes privados envolvidos e à participação dos agentes públicos, a exemplo da Lei n. 8.429/92 (Lei de Improbidade Administrativa) ${ }^{18}$. Além disso, o Superior Tribunal de Justiça possui entendimento consolidado no sentido de que numa ação de improbidade, por exemplo, a pessoa jurídica pode figurar no polo passivo, ainda que desacompanhada de seus sócios, sendo responsabilizada com seu patrimônio pela prática de ato ímprobo (Recurso Especial n. 970.393). Todavia, como expõe Luciano Moreira de Oliveira (2017, p. 161), a ação para responsabilização judicial de pessoas jurídicas com base na Lei n. 12.846/2013 é especial e, mesmo na hipótese em que o fato possa caracterizar ato de improbidade administrativa (Lei n. 8.429/1992), não é cabível a cumulação de pedidos, sob pena de se criarem obstáculos à efetividade da nova lei.

A Lei Anticorrupção também é enfática ao afirmar que dirigentes e administradores que tenham concorrido para o ilícito praticado serão responsabilizados na medida de sua culpabilidade, isso é, somente serão responsabilizados se restar comprovado que agiram com culpa ou dolo de lesionar a Administração Pública nacional ou estrangeira. No entanto, enfatiza-se que a responsabilização de dirigentes e administradores independerá da responsabilização (objetiva) da pessoa jurídica. Para mais, além do dolo e culpa, entende-se que os seguintes critérios também devem ser observados para aferir a culpabilidade dos dirigentes e administradores que lesionaram a Administração, a fim de proporcionar-lhes uma sanção adequada: (i) os motivos que os levaram à prática do ato; (ii) as circunstâncias e as consequências do ato lesivo; (iii) o comportamento concorrente da Administração Pública nacional ou estrangeira para o evento danoso; (iv) a reiteração da conduta do agente; ( $v$ ) os riscos que a conduta danosa causou aos direitos da empresa; (vi) o montante do lucro auferido; e (vii) a colaboração do dirigente ou administrador durante a apuração o ilícito. A observância desses critérios possibilitará análise mais profunda da conduta do indivíduo, permitindo que se estabeleça de forma apropriada o grau de reprovabilidade do ato ilícito praticado e, em seguida, aplicação adequada da sanção.

O referido diploma legal é constituído por sete capítulos e tem por escopo a responsabilização administrativa e civil de pessoas jurídicas pela prática de atos contra a Administração Pública, nacional ou estrangeira.

Dentre as inovações trazidas pela Lei n. 12.846/2013, estão a responsabilidade objetiva de pessoas jurídicas, o acordo de leniência, o Cadastro Nacional de Empresas Punidas - CNEP, bem como a rigidez das sanções. Todavia, a referida lei ainda deixa diversos tópicos importantes sem solução, tais como a ausência de regulamentação sobre critérios para aplicação de multa, fatos agravantes e atenuantes da pena imposta à pessoa jurídica, assim como rito e competência do procedimento administrativo.

18 Com base no art. 71 da CF e na Lei n. 8.443/92, existe também a possibilidade de o Tribunal de Contas da União imputar débitos a pessoas físicas e jurídicas responsáveis por irregularidades administrativas, como fraude à licitações e prejuízos ao erário. 
A sanção do Decreto Federal n. 8420/15 trouxe ainda: (i) a apuração da responsabilidade administrativa que será efetuada por meio de Processo Administrativo de Responsabilização (PAR); (ii) a regulamentação do acordo de leniência; (iii) a regulamentação dos Programas de Integridade; e (iv) disciplinamento de informações e sanções referentes ao Cadastro Nacional de Empresas Inidôneas e Suspensas (CEIS) e do Cadastro Nacional de Empresas Punidas (CNEP).

As sanções trazidas pela Lei Anticorrupção poderão ter natureza civil, penal e administrativa. No que tange a responsabilização da pessoa jurídica, está presente somente a responsabilização administrativa e civil. Diferentemente de nosso país vizinho, a Argentina, que em $1^{\circ}$ de dezembro de 2017, por meio da Lei n. 27.401, alterou algumas disposições relativas à corrupção já contidas no Código Criminal, estabelecendo também a responsabilidade criminal de empresas por alguns atos de corrupção, além de amplas disposições de assunção de responsabilidade e possíveis penalidades significativas em sua nova lei anticorrupção.

Não obstante o anteriormente exposto, existem certas críticas acerca da Lei Anticorrupção brasileira pois, conforme apresentado por João Pedro Ceren e Valter Moura do Carmo (2019, p. 105-106), esta, aliando-se à fórmula do Compliance que seria modificada na realidade brasileira, poderá ser utilizada como instrumento de manobra processual para aqueles que saibam usá-la, uma vez que a penalidade da multa poderá perder sua eficácia por completo ${ }^{19}$.

\subsection{A Lei das Estatais}

Outro importante marco legal na promoção de normas de integridade direcionadas ao setor público é a Lei n. 13.303/2016 ou "Lei das Estatais" que regulamentou o controle, fiscalização, a licitação e os contratos administrativos das empresas estatais.

Para José Sérgio da Silva Cristóvam e José Carlos Loitey Bergamini (2019,p. 181), a referida Lei veio a preencher um vazio legislativo de quase 18 anos, desde a Emenda Constitucional de 1998, ao estabelecer que lei dispusesse sobre o estatuto jurídico da empresa pública, da sociedade de economia mista e de suas subsidiárias que explorem atividade econômica de produção ou comercialização de bens ou de prestação de serviços, sendo uma espécie de resposta legislativa do Congresso Nacional à percepção dos brasileiros sobre a gravidade da corrupção.

Podemos citar como principais aspectos da Lei das Estatais, constante em própria exposição de motivos, sendo: a implementação de (i) normas de gestão empresarial das empresas estatais; (ii) regras de gestão de riscos e controle interno, com a diminuição da ocorrência de atos de corrupção, por meio do estabelecimento de aplicação de normas de Compliance e governança corporativa nas empresas estatais; (iii) procedimentos específicos de nomeação de dirigentes, limitando a possibilidade de indicações políticas para cargos técnicos; (iv) regras de licitações e de celebração de contratos de aquisição de bens e serviços; e (v) normas de fiscalização por parte dos órgãos de

19 A crítica realizada ao dispositivo, porém, reside na questão temporal, pois a redação textual fala que será levada em conta a "existência de mecanismos", todavia não deixa claro se deve existir previamente a prática de ilícitos previstos na própria lei anticorrupção ou se podem ser criados posteriormente, o que pode comprometer o raciocínio preventivo das medidas de Compliance (CEREN; CARMO, 2019, p.97). 
controle externo e da sociedade.

A Lei n. 13.303/2016 volta-se ao estabelecimento de mecanismos de controle de conflitos de agência, a fim de evitar a ocorrência de atos de corrupção ou desvios de recursos em empresas estatais. Nessa perspectiva, uma forma de contenção dos conflitos de agência encontrada pela lei opera-se pela imposição de práticas de Compliance, de modo a garantir que as empresas estatais sejam efetivamente fiscalizadas por agentes internos e externos à administração da sociedade estatal.

Destaca-se o art. $9^{\circ}$ da Lei das Estatais, no qual ficam estabelecidas regras gerais de adoção de práticas de gestão de riscos internos e ainda determinação pela implementação de um Código de Conduta e Integridade por parte da empresa estatal.

Uma das inovações trazidas com esse diploma legal é a manifestação pela exigência da instauração de um Comitê de Auditoria Estatutário. Os comitês de auditorias ganharam destaque com a alteração da Lei Sarbanes-Oxley, em 2002, nos Estados Unidos, onde determinou-se a obrigatoriedade de sua constituição pelas companhias abertas nacionais e estrangeiras que negociam as American Deposity Recepts (ADRs). Esse Comitê, segundo o art. 24 da Lei n. 13.303, será um órgão auxiliar do Conselho de Administração e tem como uma de suas competências fundamentais o fornecimento de informações a respeito da contratação, destituição e supervisão das atividades de auditoria independente e interna da sociedade estatal, além do recebimento de denúncias anônimas que relatem a ocorrência de atos de corrupção, ou que violem princípios ético-empresariais da empresa.

É relevante ressaltar que, primando pelo combate à corrupção nas empresas estatais, a lei dispõe ainda sobre a vedação de indicações sem qualificação técnica para o Conselho de Administração, diretores, diretor-geral e diretor-presidente. Exige-se que os indicados tenham experiência de dez anos no setor público ou privado, ou que tenham ocupado, durante um período de quatro anos, cargos relacionados com sua área de dedicação, independente se no setor público ou privado, ou, ainda, como profissionais liberais. Entre outros limites, fica ainda vedada a indicação de integrantes da administração pública, ou do órgão ao qual a sociedade estatal responde diretamente para as mencionadas funções de gestão. Ademais, segundo Marlene Kempfer e Beatriz Miranda Batisti (2017, p. 303), as balizas, a criação e o fortalecimento de órgãos de controle interno, por meio de regras de governança corporativa e práticas de gestão de riscos, traduzem esforços para a transparência e controle nos aspectos mais importantes e sensíveis da estrutura corporativa das empresas públicas e sociedades de economia mista.

De acordo com Luiza Cadar Almeida Machado Rabelo (2018, p. 237), a Lei n. 13.303/2016 tem muito a beneficiar a prestação de serviços pelo Estado, uma vez que tem intuito de incentivar as empresas estatais a atuarem em busca de mais eficiência. Além disso, entende que, apesar de existirem alguns aparentes obstáculos para a implementação do Compliance nas estatais, tal medida deve ser incentivada, para que elas aprimorem seus mecanismos de controle internos e externos e que, pautadas pela ética, consigam realizar suas atividades com qualidade.

Portanto, isto representaria um avanço jurídico para a prevenção e combate à corrupção, 
constatando-se que uma experiência da iniciativa privada foi incorporada por empresas estatais e, desta feita, estabeleceu-se uma aproximação entre os interesses públicos e privados.

\subsection{A Controladoria-Geral da União}

Ao tratarmos do Compliance na Administração Pública, não podemos deixar de enfatizar o protagonismo da Controladoria-Geral da União (CGU), haja vista as atribuições concedidas por lei ao órgão sobre essa matéria ${ }^{20}$.

Em 28 de maio de 2003, por meio da publicação da Lei n. 10.683, a então ControladoriaGeral da União, tipicamente o órgão anticorrupção do país, era encarregado de prestar assistência direta e imediata ao Presidente da República no desempenho de suas funções, desde que relativas à defesa do patrimônio público e ao incremento da transparência da gestão pública. Ainda em 2003, a Controladoria incorporou as funções da então Corregedoria-Geral da União, que tinha o propósito de combater, no âmbito do Poder Executivo Federal, a fraude e a corrupção, e promover a defesa do patrimônio público.

Após alguns anos e novas mudanças em sua estrutura, por intermédio da publicação da Lei n. 13.341, em 30 de setembro de 2016, houve a criação da Ministério da Transparência e Controladoria-Geral da União, sendo o novo órgão central do Sistema de Controle Interno e do Sistema de Correição, ambos do Poder Executivo Federal. As competências e atribuições da extinta Controladoria-Geral da União (CGU) foram, dessa forma, transferidos para esse ministério.

O então novo ministério é o órgão de controle interno do Governo Federal responsável por realizar atividades relacionadas à defesa do patrimônio público e ao incremento da transparência da gestão, por meio de ações de auditoria pública, correição, prevenção e combate à corrupção e ouvidoria. É estruturado em quatro unidades finalísticas: Secretaria de Transparência e Prevenção da Corrupção (STPC), Secretaria Federal do Controle Interno (SFC), Corregedoria-Geral da União (CRG) e Ouvidoria-Geral da União (OGU).

No entanto, por meio da Medida Provisória n. 870, de $1^{\mathrm{o}}$ de janeiro de 2019, que posteriormente seria convertida na Lei n. 13.844/2019, o órgão volta a se chamar ControladoriaGeral da União, porém, por meio do Art. 19, XVI, da referida Lei, ainda com status de Ministério. Tendo em vista a nova nomenclatura de coordenações e diretorias, efetuou-se a criação da Secretaria de Combate à Corrupção, sendo esta encarregada pelas atividades de inteligência, supervisão dos acordos de leniência, operações especiais e desenvolvimentos de outras atividades relacionadas ao combate à corrupção.

Por meio de seu sítio eletrônico, a Controladoria-Geral da União informa que realiza

20 Inobstante às ações realizadas pela CGU, aplica-se, aqui, a mesma observação sobre a relevância do Tribunal de Contas da União, cuja atuação, além do poder de sanção e da condenação ao pagamento de prejuízos ao erário, tem contribuído muito para o aperfeiçoamento do processo legislativo. A título de exemplo, segundo seu sítio eletrônico, a cada 1 real investido para seu funcionamento, o TCU retornou 32,06 reais para a sociedade em 2019, assim como foram $\mathrm{R}$ \$ 40,1 bilhões de reais economizados com as ações deste órgão (BRASIL, 2019). Para além disso, destacase que, segundo a base de jurisprudência do TCU, foram expedidos oito acórdãos com a expressão "compliance", contudo, existem outras centenas de acórdãos com determinações acerca de "conformidade", 
auditorias que avaliam a execução dos programas de governo, a gestão dos administradores e que promove ações investigativas, além de propor orientações preventivas aos gestores públicos. Mediante tais auditorias, revela-se que a CGU analisou mais de 21 mil processos (entre 2002 e 2014) tomadas de contas especiais, sendo que, desse importe, 17 mil foram encaminhados para julgamento ao Tribunal de Contas da União (TCU) e possui, desse modo, retorno potencial de R\$ 12,6 bilhões ao Tesouro Nacional. Ademais, nos últimos anos, 5.022 agentes foram punidos (demitidos, destituídos ou cassados) e 3.924 empresas foram proibidas de firmar contratos públicos.

Salienta-se também que a CGU mantém o Portal de Transparência, sendo esse um banco de dados disponível aos cidadãos sobre a aplicação dos recursos pelo Governo Federal, auxiliando na fiscalização e monitoramento das ações governamentais.

Mais restritamente ao Compliance e à prevenção a corrupção, a CGU realiza treinamentos e orientações sobre gestão de recursos públicos e é responsável em grande parte dos procedimentos presentes na Lei Anticorrupção brasileira, por intermédio de instauração e julgamento dos processos administrativos de responsabilização e celebração de acordos de leniência no âmbito do Poder Executivo Federal, além de auxiliar no fomento e na efetiva aplicação dos Programas de Integridade na Administração Pública.

\section{O PROGRAMA DE INTEGRIDADE}

Quando o órgão público decide se enquadrar no Programa de Integridade (podendo também ser referido como Plano de Integridade) e implantá-lo efetivamente, será necessário que esses conceitos sejam, de fato, tidos como fundamentos obrigatórios pelos agentes públicos. Os desenvolvedores do programa precisarão despertar entre os envolvidos o senso crítico para que eles entendam verdadeiramente a importância do programa para toda a Administração Pública. As políticas e procedimentos implementados não devem ser simplesmente normatizados pelos responsáveis esperando-se que todos agirão de forma proativa, buscando estar de acordo com uma nova diretriz advinda de um Decreto ou Portaria interna. Assim, deve haver controles e sanções aplicáveis aos que não cumprirem com o que dispõe o programa.

A Controladoria-Geral da União divulgou um “Guia Prático de Implementação de Programa de Integridade Pública” a fim de trazer orientações para a administração pública federal direta, autárquica e fundacional, segundo o disposto nos artigos 19 e 20 do Decreto n. 9.203/2017.

Como primeiro andamento, os órgãos e entidades deverão designar uma unidade à qual caberá coordenar os esforços de estruturação, execução e monitoramento de seu Programa de Integridade. Tal unidade de gestão da integridade deverá ser dotada de autonomia e de recursos materiais e humanos necessários ao desempenho de suas competências, além do acesso às demais unidades e ao mais alto nível hierárquico do órgão ou entidade.

Esse Plano de Integridade deverá previamente: (i) realizar o levantamento da situação de suas unidades de integridade, tais como o canal de denúncias e comissão de ética; (ii) realizar o levantamento de riscos para a integridade e estabelecer medidas de tratamento; e (iii) elaborar seu 
Plano de Integridade. Esse levantamento de riscos, conhecido como risk assessment nas instituições privadas, é essencial para que as organizações identifiquem seus riscos-chave e possam melhor desenvolver e endereçar os controles para diminuir ou extinguir eventuais ameaças.

Além do acima descrito, ressalta-se o apoio da alta administração, comunicações e treinamentos, ações de remediação e medidas de controle e disciplinares.

Segundo Lara Cristina de Olival Kovtunin et al (2019, p. 117), a implantação de um sistema de Compliance público objetiva a prevenção de danos ao erário, decorrentes de dispêndio desnecessário de recursos públicos, além do fortalecimento institucional, do aumento da confiança por parte da população, da maior segurança dos administradores e dirigentes, além do fomento à ética e às boas práticas de conduta na Administração Pública.

\section{BALANÇO - CINCO ANOS DA LEI ANTICORRUPÇÃO}

Passados cinco anos de seu advento, já é possível fazer um balanço dos impactos da Lei Anticorrupção no setor público e privado, bem como no cenário nacional de enfrentamento à corrupção.

Em que pese a regulamentação da Lei Anticorrupção brasileira, deve-se destacar que, até a finalização deste artigo, apenas em 13 Estados e no Distrito Federal a norma encontrava-se regulamentada.

Segundo dados da CGU (2018), ao longo dos primeiros quatro anos da vigência da aplicação propriamente dita da lei, o governo federal iniciou 183 processos contra empresas, que resultaram na aplicação de multas, que totalizaram o montante de aproximadamente R $\$ 12$ milhões. O valor apurado pela Controladoria Geral da União não considerou o valor recuperado ou evitado de ser gasto com propina, mas tão somente o valor "arrecadado" com as multas aplicadas a empresas que agiam em discordância ao disposto na Lei Anticorrupção brasileira.

Os órgãos que mais se utilizaram do diploma legal para investigação de grupos privados, com base em informações da própria CGU (2018), foram os ministérios: (i) da Fazenda, com 62 processos; (ii) de Minas e Energia, com 42; e (iii) da Saúde, com 34. Logo após, encontramos os ministérios da Justiça e Cidadania (11); Ciência, Tecnologia e Inovação e Comunicações (9); Agricultura, Pecuária e Abastecimento (8); e Educação (6). Por fim, temos Transportes, Portos e Aviação Civil (5); Planejamento, Desenvolvimento e Gestão (3); Desenvolvimento Social e Agrário (2); e Indústria, Comércio e Exterior e Serviços (1). Vale destacar que a respectiva lei só terá validade em atos ilícitos praticados após sua entrada em vigor, logo, 29 de janeiro de 2014. Um importante fato que deve também ser constatado é que o ano de 2017 corresponde a 83,6\% dos atos de investigação e punição registrados (CGU, 2018).

Estados e municípios possuem números um pouco mais tímidos. Entre eles, foram apenas 21 punições baseadas na Lei n. 12.846/13, sendo quatro publicações extraordinárias e 10 multas no valor de R \$ 8 milhões. Isso se deve principalmente pela não regulamentação da Lei Anticorrupção.

Em relação à aplicação para os agentes públicos, foi informado também pelo Ministério da 
Transparência e Controladoria Geral da União (CGU, 2018) $)^{21}$ que 506 servidores públicos federais teriam sido demitidos no ano de 2017, sendo que, desse total, 335 teriam sido expulsos em razão de prática de atos relacionados à corrupção.

Discorrendo sobre os cinco anos da Lei Anticorrupção brasileira em seu blog pessoal, o professor de Direito Administrativo da Universidade de São Paulo, Justino de Oliveira, entende que, mesmo persistindo a impressão da existência da corrupção em nosso país, existem bons resultados trazidos pela Lei Anticorrupção brasileira, tendo em vista o intenso movimento de difusão dos programas de Compliance, os eventos corporativos e científicos sobre a temática em todo o país e alianças empresariais que pretendem promover entre as empresas o princípio da anticorrupção, e outros. No setor público destaca-se a disseminação de políticas de governança e de integridade de órgãos e entidades públicas, além do estabelecimento de novos padrões de atuação e controle para empresas estatais (OLIVEIRA, 2018).

\section{CONCLUSÃO}

Por fim, é evidente que ainda temos um longo caminho a percorrer, no entanto, nota-se a direção adotada pela legislação brasileira, ainda que tardiamente, de modo a fomentar a adoção de medidas de Compliance, além de positivação de normas de integridade por parte da Administração Pública, com a implementação de estruturas com capacidade crescente de garantir os princípios constitucionais e que seguem diretrizes internacionais.

A Administração Pública, além de garantir tais princípios, deverá atender às expectativas da sociedade em relação ao exercício de sua função, fazendo-se necessário que essas demonstrem a sua preocupação e o seu comprometimento com padrões éticos, bem como com a responsabilidade, a transparência, a eficiência e a probidade no seu cotidiano. Dessa forma, o Compliance ganha cada vez mais espaço e os ideais que o permeiam são progressivamente positivados no ordenamento jurídico brasileiro.

Quanto maior a adoção de normas inclinadas à aplicação de ideais envoltos em conformidade, mais dificultoso será o emprego de atos de corrupção, tendo em vista uma estrutura de Compliance que preza pelos seguintes: (i) suporte de sua alta administração; (ii) avaliação prévia de riscos; (iii) implementação de códigos de conduta e políticas de conformidade; (iv) organização de controles internos; (v) execução de treinamentos e comunicações; (vi) existência de canais de denúncias; (vii) estruturação de investigações internas; (viii) efetiva aplicação de Due Diligence em organizações que se relacionem com a Administração Pública; (ix) monitoramento e auditoria de seu programa de Compliance.

O Compliance na Administração Pública deverá ir muito além do que um estrito legalismo e agregar uma série de valores éticos e princípios morais, devendo ter por objetivo não apenas facilitar o cumprimento da Lei, mas sim, a busca por uma estrutura transparente e sólida, que,

$2166 \%$ dos servidores federais expulsos em 2017 cometeram atos de corrupção. Ministério da Transparência e Controladoria-Geral da União. Controladoria-Geral da União. Notícias. 08 jan. 2018 (BRASIL, 2018b). 
por derradeiro, propiciará dificuldade ainda maior para atos de corrupção realizados por agentes públicos.

O combate à corrupção conduz a proveitos não só para Administração Pública, como para toda a coletividade. Ganha a administração estatal, que terá maior controle sobre atividades ilícitas, prevenindo rombos nos cofres públicos, e ganha a população que testemunhará o desenvolvimento diuturno de princípios de probidade tendentes à formação de uma cultura ética e benéfica a toda a Nação.

\section{REFERÊNCIAS}

BEZERRA, Marcos Otavio. Corrupção: um estudo sobre poder público e relações pessoais no Brasil. Rio de Janeiro: Relume Duramá, 1995.

BRASIL. Ministério da Economia. Guias da OCDE sobre a devida diligência. Brasília: ME, 2018a. Disponível em: http://www.fazenda.gov.br/assuntos/atuacao-internacional/ponto-decontato-nacional/guias-da-ocde-sobre-a-devida-diligencia Acesso em: 02 ago. 2020.

BRASIL. Ministério da Transparência e Controladoria-Geral da União (CGU). 66\% dos servidores federais expulsos em 2017 cometeram atos de corrupção. Brasília: CGU, jan. 2018b. Disponível em: http://www.cgu.gov.br/noticias/2018/01/66-dos-servidores-federaisexpulsos-em-2017-cometeram-atos-de-corrupcao. Acesso em: 10 ago. 2019.

BRASIL. Tribunal de Contas da União. Planalto lança política de governança com base em estudo do TCU. Brasília: TCU, nov. 2017. Disponível em: https://portal.tcu.gov.br/imprensa/ noticias/planalto-lanca-politica-de-governanca-com-base-em-estudo-do-tcu.htm. Acesso em: 02 ago. 2020.

CEREN, João Pedro; CARMO, Valter Moura do. Crítica ao compliance na lei brasileira de anticorrupção. Revista do Direito Público, Londrina, v. 14, n. 3, p. 87-109, dez. 2019.

COIMBRA, Marcelo de Aguiar; MANZI, Vanessa Alessi (coord.). Manual de compliance: preservando a boa governança e a integridade das organizações. São Paulo: Atlas, 2010.

CRISTÓVAM, José Sérgio da Silva; BERGAMINI, José Carlos Loitey. Governança corporativa na Lei das Estatais: aspectos destacados sobre transparência, gestão de risco e compliance.

Revista de Direito Administrativo, Rio de Janeiro, v. 278, n. 2., p. 179-210, maio/ago. 2019.

CUNHA, Matheus L. R.; EL KALAY, Marcio (org.). Manual de compliance: compliance mastermind. São Paulo: LEC, 2019. v. 1.

FARIA, Edimur Ferreira de. Governança corporativa na Administração Pública. Revista dos Tribunais, São Paulo, v. 8, p. 153-169, jan./mar. 2019.

FIESP - FEDERAÇÃO DAS INDÚSTRIAS DO ESTADO DE SÃO PAULO. Relatório corrupção: custos econômicos e propostas de combate: Índices, pesquisas e publicações. São Paulo: FIESP, maio 2012. Disponível em: http://www.fiesp.com.br/indices-pesquisas-epublicacoes/relatorio-corrupcao-custos-economicos-e-propostas-de-combate/. Acesso em: 19 jul. 
2019.

FORIGO, Camila Rodrigues. Controle da corrupção na Administração Pública: uma perspectiva através do Compliance. Revista dos Tribunais, São Paulo, v. 153, p. 17-40, mar. 2019.

KEMPFER, Marlene; BATISTI, Beatriz Miranda. Estudos sobre o compliance para a prevenção da corrupção nos negócios públicos: ética, ciência da administração e direito. Revista do Direito Público, Londrina, v. 12, n. 2, p. 273-307, ago. 2017.

KLITGAARD, Robert. A corrupção sob controle. Rio de Janeiro: Jorge Zahar Editor, 1994.

KOVTUNIN, Lara Cristina de Olival; LIMA, Karla Kellem de; BEZERRA Maria Marciária Martins; SANTOS JÚNIOR Ronaldo Rosa dos. Programas de compliance no setor público: instrumento de combate à corrupção e incentivo à transparência. Revista São Luís Orione, Araguaína, v. 2, n. 14, p. 108-120, 2019.

MEIRELLES, Hely Lopes. Direito administrativo brasileiro. 34. ed. São Paulo: Malheiros Editores, 2008.

MOREIRA, Joaquim Manhaes. A ética empresarial no Brasil. São Paulo: Atlas, 2002.

NASCIMENTO, Victor Hugo Alcalde do. Os desafios do compliance contemporâneo. Revista dos Tribunais, São Paulo, v. 1003, p. 51-75, maio 2019.

OECD - ORGANIZAÇÃO PARA ECONOMIA COOPERAÇÃO E DESENVOLVIMENTO. CleanGovBiz: integrity in practice. Paris: OECD, 2014. Disponível em: https://www.csrhellas. net/network/wp-content/uploads/media/Anti-corruption_ISO.pdf. Acesso em: 02 ago. 2020.

OLIVEIRA, Justino. Lei Anticorrupção Brasileira completa 5 anos: a corrupção diminuiu? In: Blog Justino de Oliveira, São Paulo, 12 ago. 2018. Disponível em: https://blogdojustino.com. br/lei-anticorrupcao-brasileira/. Acesso: 19 jul. 2019.

OLIVEIRA, Luciano Moreira de. Autonomia da ação de responsabilidade de pessoas jurídicas no Brasil com fundamento na Lei n. ${ }^{\circ}$ 12.846/2013. Revista de Direito Administrativo, Rio de Janeiro, v. 276, p. 147-163, set./dez. 2017.

RABELO, Luiza Cadar Almeida Machado. Compliance nas empresas estatais: aplicação da Lei 13.303/2016. Revista de Direito da Administração Pública, Rio de Janeiro, v. 1, n. 2, p. 221 239, jul./dez. 2018.

SAAD-DINIZ, Eduardo. Brasil vs. Golias: os 30 anos da responsabilidade penal da pessoa jurídica e as novas tendências em Compliance. Revista dos Tribunais, São Paulo, v. 988, p. 2553, fev. 2018.

SANTOS, Euni. Os nove pilares de um programa de compliance. 2017. Disponível em: https://qfsconsulting.com.br/xiii-workshop-de-compliance-os-9-pilares/. Acesso em:19 jul. 2019.

VALLE, Vanice Regina Lírio do; SANTOS, Marcelo Pereira dos. Governança e Compliance na Administração Direta: ampliando as fronteiras do controle democrático. Revista de Direito 
Administrativo e Constitucional, Curitiba, ano 19, n. 75, p. 161-177, jan./mar. 2019.

Como citar: VAZ, Thiago; MASTRODI, Josué. O compliance na Administração Pública: a realidade brasileira submetida a normas de integridade. Revista do Direito Público, Londrina, v. 16, n. 2, p. 64-89, ago. 2021. DOI: 10.5433/24157-108104-1.2021v16n2p. 64. ISSN: 1980-511X

Recebido em: 28/08/2019

Aprovado em: 24/08/2020 